\title{
金めっき浴中における銅不純物の電解除去による管理技術
}

\author{
伊達 和宏*, 吉原 佐知雄 *, 野澤 純一 **, 野尻 尚克**
}

\section{Bath Control Technique by Electrowinning of Copper Ion Impurities in the Process of Gold Plating}

Kazuhiro DATE*, Sachio YOSHIHARA*, Junichi NOZAWA**, and Naokatsu NOJIRI**

\footnotetext{
* 宇都宮大学大学院工学研究科学際先端システム学専攻（） 321-8585 栃木県宇都宮市陽東 7 丁目 1-2）

*** 株式会社大昌電子（† 321-1274 栃木県日光市土沢 1383）

* Department of Advanced Interdisciplinary Sciences, Graduate School of Engineering, Utsunomiya University (7-1-2, Yoto, Utsunomiya-shi, Tochigi 321-8585)

*** Tochigi Plant, DAISHO DENSHI CO., Ltd. (1383, Dosawa, Nikko-city, Tochigi 321-1274)
}

\begin{abstract}
There are so-called wire bonding methods to electrically connect semiconductor IC chips and printed wiring boards. Typically, gold plating is applied to the connection terminal pad on the wiring board, and the higher the purity of the plated gold film, the higher the connection strength of the wire and the better the long term reliability. But in the process of manufacturing printed wiring boards, it is impossible to completely avoid impurities in the plating bath. In this study, we removed impurities in the gold plating bath using constant potential electrolysis at several different electrode potentials, and we discuss the performance of this technique for the removal of impurities in the gold plating bath.
\end{abstract}

Key Words: Electrowinning, Gold, Copper, Wire Bonding, Printed Wiring Board, ICP

\section{1. 緒 言}

現在，科学技術の発展に伴う電子機器の大量生産によっ てプリント配線板の生産量は日に日に増加している。ま た, 小型化, 高性能化に伴い電子機器 1 台に搭載される半 導体 IC チップ数も増え, 携帯電話を例に挙げると, 1 台あ たり約 20 個もの半導体チップが搭載されている。

プリント配線板と半導体 ICチップとの電気的接続法の一 つにワイヤボンディングがある。配線板表面のワイヤボン ディングを行う接続端子には通常, 金めっきが施される。 このとき，金めっき皮膜中の金純度が高いほどワイヤーの 接続強度も高くなり, 製品は高い長期寿命信頼性を得るこ とができるが，実際のプリント配線板製造工程において， めっき浴中に不純物を持ち込まないというのは不可能に近 いのが現状である ${ }^{1) \sim 3) 。 ~}$

特に金のワイヤボンディングではめっき浴に銅不純物が 混入することで金表面が污染され，ボンディング強度を低 下させると考えられているが, 具体的にどの程度不純物が 混入すれば強度が低下するのか, どのように污染されてい るのかなどは現場の経験則によって決定されることが多 い。現在, 浴中のより効果的な不純物除去法がないか研究 されている。そこで本研究では, 異なる電位で金めっき浴 中の銅不純物除去を定電位電解除去により行い, 電解採取 後の採取電極を溶解して ICP 発光分光分析により採取物の 定性・定量を行った。

\section{2. 実験方法}

\section{1 定電位条件下での電解採取条件 ${ }^{4), 5}$}

純粋な金めっき浴であるシアン化第一金カリウム系中性 金めっき浴（以後 $0 \mathrm{ppm}$ 浴と称す）に, 硫酸銅 5 水和物 $\left(\mathrm{CuSO}_{4} \cdot \mathrm{H}_{2} \mathrm{O}\right)$ を用いて, 銅イオンをそれぞれ 10, $20 \mathrm{ppm}$ 含 有した金めっき浴（それぞれ $10 \mathrm{ppm}$ 浴, $20 \mathrm{ppm}$ 浴）を調 製，使用した（Table 1 参照）。

測定試料の種類は, 実際の電解除去による銅回収効果に ついて検討を行うため $10 \mathrm{ppm}$ 浴, $20 \mathrm{ppm}$ 浴 $(300 \mathrm{ml})$ にて, 浴温は $25^{\circ} \mathrm{C}$ に設定した。他の実験条件については，対極 に $\mathrm{Pt}$ 板，参照電極に飽和 $\mathrm{Ag} / \mathrm{AgCl}$, 作用極にあらかじめス トライク金めっきを施した Ni 板を用いた。本研究では, 作 用極の Ni と浴中の金との置換めっきが起こると, イオン化 傾向から Ni が浴中に溶け出し, 浴中における不純物濃度が 高くなってしまう。

そのため $\mathrm{Ni}$ 表面とめっき浴との反応ではなく, 金表面と 浴との反応を見る必要があるので金ストライクめっきを行っ

Table 1. Basic composition of the bath for gold plating

\begin{tabular}{c|c}
\hline $\mathrm{K}\left\lceil\mathrm{Au}(\mathrm{CN})_{2}\right\rceil$ & $6 \sim 6.5 \mathrm{~g}\left(0.04 \mathrm{~mol} / \mathrm{dm}^{3}\right)$ \\
\hline $\mathrm{C}_{6} \mathrm{H}_{5} \mathrm{~K}_{3} \mathrm{O}_{7}$ & $0.15 \mathrm{~mol} / \mathrm{dm}^{3}$ \\
\hline $\mathrm{C}_{6} \mathrm{H}_{8} \mathrm{O}_{7}$ & $0.05 \mathrm{~mol} / \mathrm{dm}^{3}$ \\
\hline $\mathrm{Tl}_{2} \mathrm{SO}_{4}$ & $1.98 \times 10^{-4} \mathrm{~mol} / \mathrm{dm}^{3}$ \\
\hline $\mathrm{pH}$ & $6.1 \sim 6.4$ \\
\hline Relative density & $1.1 \sim 1.2 \mathrm{~g} / \mathrm{ml}$ \\
\hline
\end{tabular}


た。使用する浴は不純物が一切混入していない $0 \mathrm{ppm}$ 浴 (Table 1 参照) において, 浴温 $60^{\circ} \mathrm{C}$, 電流密度 $1.0 \mathrm{~mA} / \mathrm{cm}^{2}$ で $100 \mathrm{~s}$ 行った。電解時の攪捧については無攪拌で行った。

また, 測定結果の誤差をなるべく抑えるために電解時間 を 120 分に設定し，実験を行った。設定電位は定電位 -0.6 $\mathrm{V},-0.55 \mathrm{~V},-0.5 \mathrm{~V},-0.4 \mathrm{~V}$ (それぞれvs. $\mathrm{Ag} / \mathrm{AgCl}$ ) の 4 パターン測定した。

\section{2 電解採取電極のICP による分析}

ICP で測定する試料は溶液でなければならないので, 皮 膜を王水によって溶解した。王水は濃塩酸: 濃硝酸 $=3: 1$ を混合し, 溶液が無色から赤橙色になるまで軽く攪拌し待 つことで作製した。

次に $50 \mathrm{ml}$ ビーカー内に 2.1 で記した定電位電解採取を 行った基板のマスキングテープを全て剥がし, 皮膜部分 $1.5 \times 1.5 \mathrm{~cm}^{2}$ 部位をイオン交換水ですすぎ入れる。この ビーカーに王水を入れることで溶解させるのだが, 王水は 非常に酸化力が強い溶液であるため ICP 装置への負担を考 慮し添加する王水は $4 \mathrm{ml}$ に抑えた。

王水をビーカー内に $10 \mathrm{ml}$ メスピペットを用いて入れる とただちに反応が始まり, 容器を定期的に攪挥すること で, 室温にて約 $10 \mathrm{~h}$ ほどで下地の $\mathrm{Ni}$ を含め完全に基板は 溶解した。この王水に溶解させた試料溶液 $1 \mathrm{ml}$ を $100 \mathrm{ml}$ メスフラスコに洗い込みメスアップすることで測定用の試 料溶液を作製した。

このような操作で $0,10,20 \mathrm{ppm}$ の試料に対する分析溶 液を調製したが，他にストライク金めっきのみを行い電解 採取していない $\mathrm{Ni}$ 板の試料溶液も同様な操作で作製した。 これはバックグラウンドのデータとして使用した。

\section{3 標準溶液作製}

ICP 測定にはあらかじめ濃度が分かっている標準溶液が 検量線を作製するために必要である。複数の原子を定量す るにはどちらのイオンも存在する混合溶液でなければなら ない。今回の測定では金と銅の定量を行うので以下のよう な手順で標準溶液を作製した。

元となる希釈していない原子吸光分析用標準溶液, $\mathrm{Cu}$ $1,000 \mathrm{ppm}$ と Au 1,000 ppm（関東化学製）を準備し，それぞ れ $10 \mathrm{ml}$ メスピペットを使用して計り取りそれを $100 \mathrm{ml}$ の メスフラスコに入れてメスアップした。この溶液を ATT （アテネーター）溶液 (Au:100 ppm Cu:100 ppm) とし, さら にメスフラスコ，原子吸光分析用標準溶液， $\mathrm{Cu}$ 1,000 ppm と $\mathrm{Au} 1,000 \mathrm{ppm}$ 溶液を用いて $\mathrm{Au} 10 \mathrm{ppm}, 1 \mathrm{ppm}, \mathrm{Cu} 10$ ppm, Cu 1 ppm 溶液の 4 つの標準溶液を作製した。また,

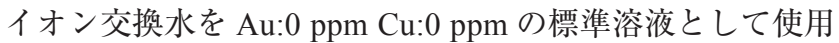
した。

\section{3. 結果と考察}

ICP による金と銅の定量結果を Table 2 に， Ni 基板のバッ クグラウンド值を差し引いたデータを Table 3 に示した。
Table 2. ICP data for each specimen

\begin{tabular}{l|c|c}
\hline $\begin{array}{l}\text { Strike gold plated } \\
\text { Nickel substrate }\end{array}$ & $\mathrm{Au}[\mathrm{ppm}]$ & $\mathrm{Cu}[\mathrm{ppm}]$ \\
\hline $\begin{array}{l}\text { Ion concentration } \\
\text { Cathode potential }\end{array}$ & & 0.14 \\
\hline $\begin{array}{l}20 \mathrm{ppm} \\
-0.6 \mathrm{~V}\end{array}$ & 19.52 & 3.00 \\
\hline $\begin{array}{l}20 \mathrm{ppm} \\
-0.55 \mathrm{~V}\end{array}$ & 11.01 & 4.06 \\
\hline $\begin{array}{l}20 \mathrm{ppm} \\
-0.5 \mathrm{~V}\end{array}$ & 4.72 & 3.28 \\
\hline $\begin{array}{l}20 \mathrm{ppm} \\
-0.4 \mathrm{~V}\end{array}$ & 5.39 & 3.12 \\
\hline $\begin{array}{l}10 \mathrm{ppm} \\
-0.6 \mathrm{~V}\end{array}$ & 14.86 & 2.99 \\
\hline $\begin{array}{l}10 \mathrm{ppm} \\
-0.55 \mathrm{~V}\end{array}$ & 8.21 & 3.32 \\
\hline $\begin{array}{l}10 \mathrm{ppm} \\
-0.5 \mathrm{~V}\end{array}$ & 8.47 & 3.30 \\
\hline $\begin{array}{l}10 \mathrm{ppm} \\
-0.4 \mathrm{~V}\end{array}$ & 4.02 & 3.15 \\
\hline
\end{tabular}

Table 3. ICP data after calibration of background for each specimen

a) $20 \mathrm{ppm}$ bath, b) $10 \mathrm{ppm}$ bath

\begin{tabular}{l|c|c}
\hline $\begin{array}{l}\text { Ion concentration } \\
\text { Cathode potential }\end{array}$ & $\mathrm{Au}[\mathrm{ppm}]$ & $\mathrm{Cu}[\mathrm{ppm}]$ \\
\hline $\begin{array}{l}20 \mathrm{ppm} \\
-0.6 \mathrm{~V}\end{array}$ & 18.54 & 2.86 \\
\hline $\begin{array}{l}20 \mathrm{ppm} \\
-0.55 \mathrm{~V}\end{array}$ & 10.03 & 3.92 \\
\hline $\begin{array}{l}20 \mathrm{ppm} \\
-0.5 \mathrm{~V}\end{array}$ & 3.74 & 3.14 \\
\hline $\begin{array}{l}20 \mathrm{ppm} \\
-0.4 \mathrm{~V}\end{array}$ & 4.41 & 2.98 \\
\hline
\end{tabular}

b)

\begin{tabular}{l|c|c}
\hline $\begin{array}{l}\text { Ion concentration } \\
\text { Cathode potential }\end{array}$ & $\mathrm{Au}[\mathrm{ppm}]$ & $\mathrm{Cu}[\mathrm{ppm}]$ \\
\hline $\begin{array}{l}10 \mathrm{ppm} \\
-0.6 \mathrm{~V}\end{array}$ & 13.88 & 2.85 \\
\hline $\begin{array}{l}10 \mathrm{ppm} \\
-0.55 \mathrm{~V}\end{array}$ & 7.23 & 3.18 \\
\hline $\begin{array}{l}10 \mathrm{ppm} \\
-0.5 \mathrm{~V}\end{array}$ & 7.49 & 3.16 \\
\hline $\begin{array}{l}10 \mathrm{ppm} \\
-0.4 \mathrm{~V}\end{array}$ & 3.04 & 3.01 \\
\hline
\end{tabular}

さらに，今回の測定目的は定電位電解除去法による銅回 収効率の効果であるので，電解前の浴中の銅の質量に対す る銅除去量の割合を除去率 [\%] として算出した。算出し た銅除去量，除去率を Table 4, Fig. 1２に示した。

そのことを考虑した上で今回の測定結果から，除去量， 除去率という観点から見てみると $-0.55 \mathrm{~V}$ のときに除去量, 除去率ともに最も高い值を示した。これは異種金属が存在 しているめっき浴においては，銅の析出電位は理論電位 $(-0.4 \mathrm{~V})$ よりも卑側にシフトし, $-0.55 \mathrm{~V}$ が最適電位に近い

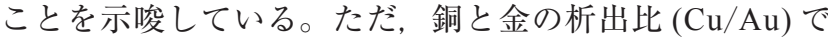
は， $-0.5 \mathrm{~V}(20 \mathrm{ppm}),-0.4 \mathrm{~V}(10 \mathrm{ppm})$ の方が大きくなって おり，有効成分の金の析出も多く，実際の適用に当たって 
Table 4. Removal amount and ratio of copper for each bath a) $20 \mathrm{ppm}$ bath, b) $10 \mathrm{ppm}$ bath

a)

\begin{tabular}{l|c|c}
\hline $\begin{array}{l}\text { Ion concentration } \\
\text { Cathode potential }\end{array}$ & $\begin{array}{c}\text { Removal amount } \\
{[\mathrm{mg}]}\end{array}$ & $\begin{array}{c}\text { Removal ratio } \\
{[\%]}\end{array}$ \\
\hline $\begin{array}{l}20 \mathrm{ppm} \\
-0.6 \mathrm{~V}\end{array}$ & 1.14 & 19 \\
\hline $\begin{array}{l}20 \mathrm{ppm} \\
-0.55 \mathrm{~V}\end{array}$ & 1.57 & 26.2 \\
\hline $\begin{array}{l}20 \mathrm{ppm} \\
-0.5 \mathrm{~V}\end{array}$ & 1.26 & 21 \\
\hline $\begin{array}{l}20 \mathrm{ppm} \\
-0.4 \mathrm{~V}\end{array}$ & 1.19 & 19.8 \\
\hline
\end{tabular}

\begin{tabular}{l|c|c}
\hline \multicolumn{3}{l}{ b) } \\
\hline $\begin{array}{l}\text { Ion concentration } \\
\text { Cathode potential }\end{array}$ & $\begin{array}{c}\text { Removal amount } \\
{[\mathrm{mg}]}\end{array}$ & $\begin{array}{c}\text { Removal ratio } \\
{[\%]}\end{array}$ \\
\hline $\begin{array}{l}10 \mathrm{ppm} \\
-0.6 \mathrm{~V}\end{array}$ & 1.14 & 38 \\
\hline $10 \mathrm{ppm}$ & 1.27 & 42.3 \\
$-0.55 \mathrm{~V}$ & 1.26 & 42 \\
\hline $\begin{array}{l}10 \mathrm{ppm} \\
-0.5 \mathrm{~V}\end{array}$ & 1.20 & 40 \\
\hline $10 \mathrm{ppm}$ & & \\
$-0.4 \mathrm{~V}$ &
\end{tabular}

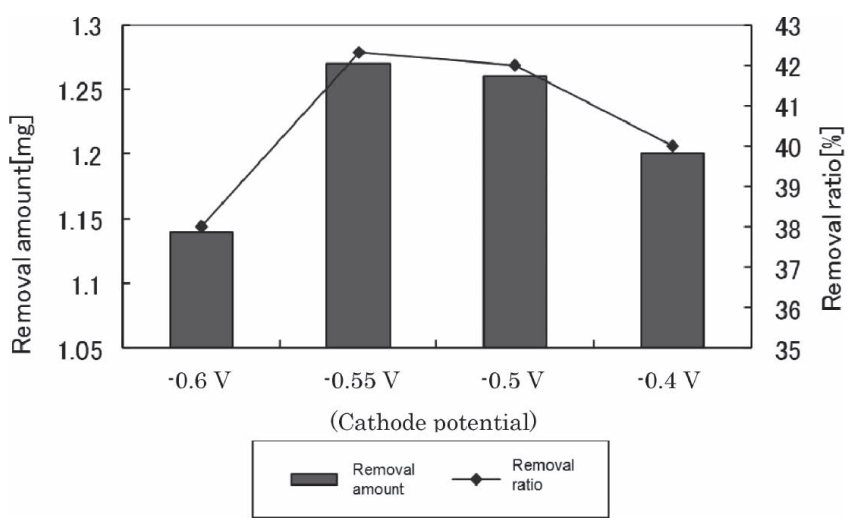

Fig. 1 Removal amount and ratio of copper for $10 \mathrm{ppm}$ bath within 120 mins

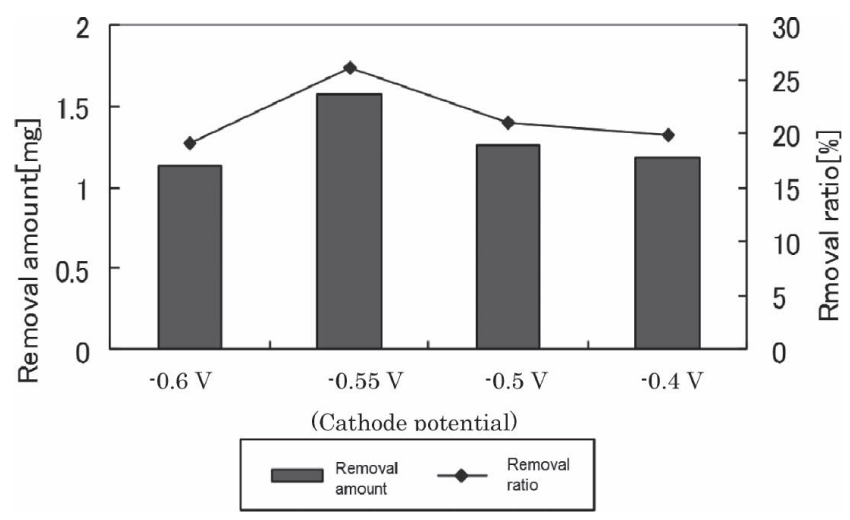

Fig. 2 Removal amount and ratio of copper for $20 \mathrm{ppm}$ bath within 120 mins
の電位設定については，目的によって判断する必要がある。 除去量という観点からは，より多くの銅を回収するため には $-0.55 \mathrm{~V}$ にてより長い電解時間を必要とすることが問 題点として明らかになった。

\section{4. 結 論}

本研究では，実用的な現場において金ワイヤーボンディ ング用パッド用の電解金めっき浴中の不純物として銅イオ ンの濃度を実際混在すると考えられる範囲で変化させ，電 位を変化させ不純物である銅イオンの電解除去実験を行っ た。その結果, 除去量, 除去率という観点から見てみると $-0.55 \mathrm{~V} v s . \mathrm{Ag} / \mathrm{AgCl}$ のときに除去量, 除去率ともに最も高 い值を示した。

(2014.2.6- 受理)

\section{文献}

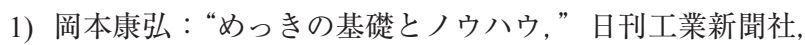
p. 120,2009

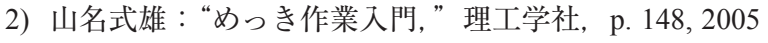

3) 青谷 薰, 今井雄一, 川合 慧: “金属メッキ技術, ” 槇書 店, pp. 189-190, 1979

4) D. T. Sawyer, A. Sobkowiak, and J. L. Roberts, Jr.: “電気化学測 定法の基礎,”丸善, p. 43, 2003

5) 電気化学会 : “電気化学測定マニュアル基礎編, ”丸善, p. 53,2002

著者紹介

伊達和宏（だて かずひろ

吉原佐知雄（よしはらさちお

野澤純一（のざわ じゅんいち

野尻尚克（のじり なおかつ） 